\title{
Toward an Ecological Understanding of Intimate Partner Sexual Violence
}

Laura Tarzia'

'Department of General Practice, The University of Melbourne, VIC, Australia laura.tarzia@unimelb.edu.au

\section{Introduction}

Intimate partner sexual violence (IPSV) is a hidden form of violence against women (Easteal \& McOrmond-Plummer, 2006). Whilst the most extreme manifestation of this violence is rape and sexual assault, women can experience a range of more complex and subtle behaviours including: the use of coercion, threats or blackmail to obtain sexual acts; forced consumption of pornography; and reproductive abuse (Bagwell-Gray, Messing, \& Baldwin-White, 2015; Tarzia, Wellington, Marino, \& Hegarty, 2018). These behaviours may be experienced alongside physical, emotional, or financial abuse by a partner or ex-partner (Black et al., 2010; World Health Organization, 2013), or they may occur in isolation. Globally, we know that one in three women has experienced physical or sexual violence at the hands of an intimate partner in their lifetime (World Health Organization, 2013), but disaggregated data for sexual violence alone is not available. BagwellGrey and colleagues (2015) in a recent review of the IPSV literature in the US, found mean average prevalence rates of around $10 \%$ across included studies. Similar rates have been reported in Australia (Cox, 2015). These rates, however, are likely to be under-representations due to the stigma and silence surrounding this issue (Wall, 2012).

Despite its prevalence, IPSV is poorly understood and under-researched (Logan, Walker, \& Cole, 2015). It is most commonly discussed either within the broader spectrum of intimate partner violence (IPV), or as a form of sexual assault, without examining its particular contextual factors (Bagwell-Gray et al., 2015). However, the experience of sexual violence within an intimate relationship is likely to differ substantially from the experience of physical or emotional abuse (Katz, Moore, \& May, 2008). For instance, women frequently describe the humiliation and betrayal of trust that accompanies rape or assault by an intimate partner (Easteal \& McOrmondPlummer, 2006) and often will not disclose sexual abuse even when physical abuse by the partner is revealed (Wall, 2012). Similarly, sexual violence at the hands of an intimate partner differs greatly from rape or assault by a stranger, with women being far less likely to disclose the former compared to the latter (Cox, 2015; Wall, 2012). Consequently, studies show that IPSV can lead to more severe mental health outcomes for women than other types of SV (Tarzia, Thuraisingam, et al., 2018). IPSV is also associated with a higher risk of homicide than other types of violence (Campbell \& Soeken, 1999), as well as with unwanted pregnancies (Basile et al., 2018).

Given the serious and wide-ranging harms of IPSV, it is critical that prevention and early engagement efforts are targeted to maximise effectiveness. This requires an understanding of the 
individual, relationship, community and societal factors that contribute to IPSV, and how these intersect. This "ecological" approach, first used in the context of violence against women by Heise (1998) (see Figure 1) has been useful in guiding prevention efforts in Australia (Our Watch, Australia's National Research Organisation for Women's Safety (ANROWS), \& VicHealth, 2015) and internationally (World Health Organisation (WHO) \& London School of Hygiene and Tropical Medicine, 2010; World Health Organization, 2010). Yet, to date this work has focused only on IPV and SV more broadly; IPSV has largely been left out of the theoretical development of ecological models and their application in practice. This obfuscates the unique harm that IPSV causes to women (McOrmond-Plummer, 2014) and may reduce the effectiveness of prevention and response efforts. While some of the causes and dynamics will certainly be common to IPV, SV and IPSV (Malamuth, Sockloskie, Koss, \& Tanaka, 1991), there are other variables at the individual, relationship, community and societal levels that specifically promote the use of sexual violence within heterosexual intimate relationships (McOrmond-Plummer, 2014). Logan and colleagues (2015), for instance, have identified some of these factors in their review of the literature, including the notion that sex within relationships is a private matter; that "real rape" is only perpetrated by strangers in dark alleyways; and the belief that sex within a marriage is a "wifely duty". Additional factors as yet unexamined within the extant literature include cultural beliefs and norms around gender and sexual behaviour, whereby men are assumed to be naturally sexually insatiable, whilst women secretly enjoy being sexually pursued (Tarzia, 2015). The burgeoning and increasingly violent pornography industry (Cramer et al., 1998), as well as social acceptance of the commodification of women's bodies (Simmons, Lehman, \& Collier-Tenison, 2008) may also play a role in the normalisation of men's sexual violence against their intimate partners. These factors have been largely unrecognised within broader ecological frameworks and prevention efforts, although some have been addressed in sexual assault programs, particularly for younger people. 


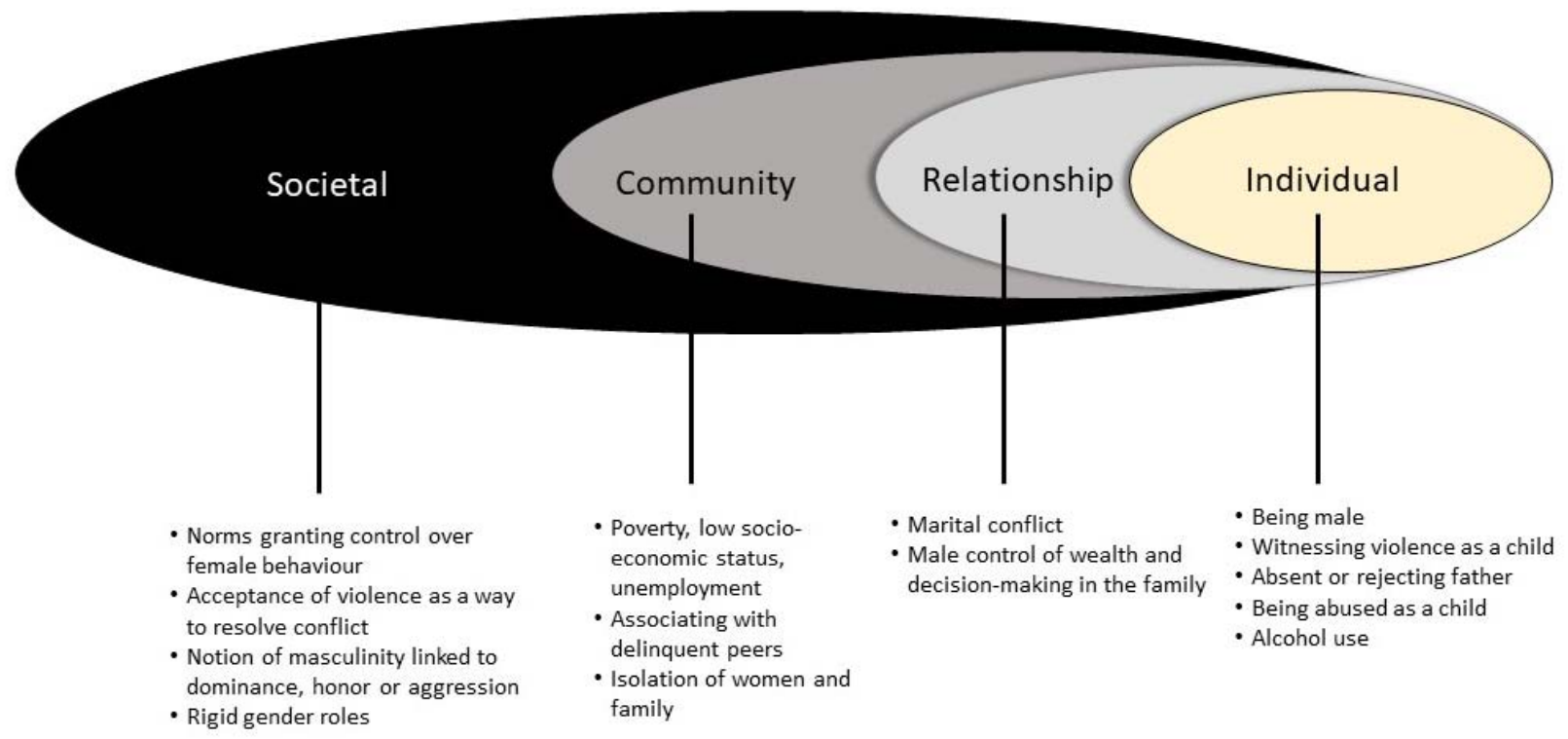

Existing ecological models and theories generally draw on global studies and robust quantitative evidence to determine which factors might be predictive of men's violence against women (Fulu \& Miedema, 2015; Heise, 1998; Reilly \& Gravdal, 2012), however, we have no such evidence base in the context of IPSV. Instead, in this paper qualitative interviews with victim/survivors are drawn on to identify what factors might be relevant within an ecological framework. Specifically, the guiding research question for this study was: "How do women understand and situate IPSV within an ecological framework of individual, relationship, community and societal factors?" Although this evidence has not been tested empirically at the population level and represents only the participants' perceptions of the causes of IPSV, it is important to recognise lived experience as a valuable form of knowledge with much to offer in understanding this complex and hidden problem (Tarzia, Humphreys, \& Hegarty, 2017).

\section{Methods}

This study is part of a larger project exploring women's experiences of IPSV. In-depth unstructured interviews were conducted with female survivors in Australia; the data for this paper focus on the individual and relationship context and socio-cultural factors that may have been associated with sexual violence within their intimate relationships. Some of these factors were explicitly identified by the women themselves, and others have been extrapolated from the women's narratives.

\section{Recruitment}

Women were recruited via advertisements placed on Facebook. The advertisements used sensitive language recognising that many women would not be ready to name their experiences as "rape", "sexual assault" or "violence". Instead we asked, "Have you ever been in a relationship where 
things happened in the bedroom that you didn't want?" and "Have you ever felt pressured, unsafe or afraid during sex with a boyfriend, girlfriend, husband or partner?" Two women's domestic violence organisations with whom the author had an existing relationship were asked to post the ad on their pages. Clicking on the ad redirected participants to an online expression of interest form, where they were asked to input their first name and a safe telephone number and email address (for a discussion on the use of safe contact details see (Tarzia, Valpied, Koziol-McLain, Glass, \& Hegarty, 2017)). A research assistant then followed up with the women to confirm interest, send through the study Plain Language Statement and consent form, and arrange a convenient interview time.

\section{Data Collection}

In-depth, unstructured interviews were conducted between October 2017 and March 2018. The researcher simply asked participants, "Can you tell me about a time in a relationship when something happened sexually that you didn't want, and any background to that relationship?" Interviews were conducted face-to-face where possible, however, several women preferred to speak over the telephone. Studies confirm that, providing rapport is established, telephone interviews can be a useful method of data collection on sensitive topics because the lack of visual cues adds emotional distance (Mealer, 2013). Interviews lasted between 22 minutes and 83 minutes with an average length of 45 minutes. They were audio recorded and transcribed verbatim.

\section{Data Analysis}

Both inductive and deductive analysis methods were utilised in this study. In the first stage, the interview data were analysed thematically following Braun and Clarke's (2019) reflexive approach. Typically, this type of thematic analysis involves reading and re-reading of interview transcripts to familiarise oneself with the data before undertaking three levels of coding (descriptive, interpretative and thematic) followed by critical reflection and refinement. In this case, however, only descriptive and interpretative codes were driven by the data. These codes were then mapped on to the ecological framework and grouped under individual, relationship, community and societal factors.

\section{Ethical and Safety Considerations}

Given the sensitivity of the topic, a range of protocols were followed to ensure that women's safety and wellbeing were protected. As mentioned previously, safe telephone numbers and email addresses were requested from all participants. Facebook recruitment was carried out via pages that a woman had already "liked" rather than creating a new page for the project. This meant that no additional risk was created for participants. A generic email address was used for all communication about the study and email subject headers referred to a "women's health project". These strategies have been used previously by the author in similar research in this area and are described in detail elsewhere (Tarzia, Valpied, et al., 2017).

The author is an experienced interviewer who has worked in the area of violence and abuse for many years; nonetheless, a distress protocol was developed in the event that any participant 
disclosed that she was unsafe or became unduly distressed. Resource cards with contact details for specialist services for sexual assault, IPV, and mental health were provided to all participants at the conclusion of the interview. The author followed up with participants a few days after the interview to check in and make sure they were not experiencing any negative effects. A small gift voucher was provided to the participant at this time as a small token of appreciation for their contribution to the project.

The study received clearance from The University of Melbourne Human Research Ethics Committee (HREC \#1749979).

\section{Findings}

Thirty-eight women took part in an interview. Most had completed some form of higher education, were currently employed, and spoke English as a first language. Approximately half were studying. Not all the women identified as heterosexual, however, all of the experiences of IPSV had been perpetrated by a male partner. None of the women identified as Aboriginal or Torres Strait Islander. All of the women except one had left the partner who perpetrated the IPSV.

Table 1. Participant demographics $(\mathrm{n}=38)$

\begin{tabular}{|l|l|l|}
\hline Age & 13 & $34 \%$ \\
$18-29$ & 21 & $55 \%$ \\
$30-49$ & 3 & $8 \%$ \\
$50-64$ & 1 & $3 \%$ \\
65 and older & 9 & $24 \%$ \\
\hline Living with a disability & 27 & $71 \%$ \\
Yes & & \\
No & 15 & $39 \%$ \\
\hline Currently in an intimate relationship & 23 & $61 \%$ \\
Yes & & \\
No & 19 & $50 \%$ \\
\hline Marital Status & - & \\
Never married & 16 & $42 \%$ \\
Widowed & 3 & $8 \%$ \\
Divorced/Separated & & \\
Married & 24 & $63 \%$ \\
\hline Highest Education & 7 & $18 \%$ \\
Finished degree/higher degree & 1 & $3 \%$ \\
Completed some secondary schooling & 6 & $16 \%$ \\
Completed traineeship & & \\
Diploma & 17 & $45 \%$ \\
\hline Occupational Status & 7 & $18 \%$ \\
Part-time/casual employment & 10 & $26 \%$ \\
\hline Unemployed & \multicolumn{2}{|l}{} \\
Full-time employment &
\end{tabular}




\begin{tabular}{|l|l|l|}
\hline Working unpaid (including home duties) & 2 & $5 \%$ \\
Retired & 1 & $3 \%$ \\
Self employed & 1 & $3 \%$ \\
\hline Main source of Income & & \\
Wages or salary & 24 & $63 \%$ \\
Pension or benefit & 12 & $32 \%$ \\
Other & 2 & $5 \%$ \\
\hline
\end{tabular}

\section{Individual Factors - Victim/Survivors}

The majority of the participants self-identified as being vulnerable in some way to being taken advantage of by a partner. Their vulnerabilities included mental health issues and physical disabilities. However, two main factors stood out as being central to IPSV victimisation:

\section{Past sexual assault or abuse}

Many of the participants had experienced sexual, physical or emotional abuse in their family of origin. Several had been sexually abused as children. Others had experienced sexual assault as young adults, perpetrated by strangers, acquaintances, or a previous intimate partner. This frequently led to poor self-esteem and a lack of knowledge about healthy sexual relationships that was readily exploited by the perpetrator. For instance, women's trauma from the past abuse was used as an excuse for why they did not enjoy the sexual acts they were being forced to perform by their partners.

I was sexually assaulted by my brother when I was nine - sexually assaulted, sexually manipulated, sexually - I don't know what the word is - experimented on maybe, that's a better word - so I kind of thought that sex was always just part of pleasing men. Then I was sexually assaulted when I was 15 by five men, so it just kind of went on. To me, sex was just something that as a female I had to do, I had to perform. (GP)

I saw my own mother being forced to do things, so I thought that was normal and then when I found out it wasn't normal, it was a bit too late. So, it would always end up, in the back of your mind, you either do what they want and not say anything, or you get beaten up or screamed at. (TT)

I was sexually assaulted before I met [my partner]. That's why it was really easy for him to convince me they're all your issues...He'd imply that that's why. I haven't dealt with it properly, so that's why I couldn't perform the way he wanted me to. (TV)

\section{Sexual inexperience}

Many of the participants stated that they were naïve and inexperienced upon entering the relationship with their partner. Most were extremely young at the time and had not had a previous 
healthy relationship or sexual encounter. This made it very difficult for them to get a sense of what was normal sexual behaviour in relationships, leaving them reliant on the abusive partner to set the standard.

I was married two days after my eighteenth birthday. I knew nothing. (EK)

I was a virgin and I was a good Catholic. (BK)

I was 19 when we first got together and I'd one boyfriend prior to that which was at university and we were together for about three months...I was pretty inexperienced. He was my first boyfriend, my first sexual partner and then my [abusive] ex-partner's my second sexual partner. So I was a bit in the dark with what was normal and what was not normal and I guess I was pretty innocent growing up because, yeah, I didn't have sex until I was 19. (MW)

He [abusive partner] managed to convince me... he was my frame of reference for what was an okay, reasonable behaviour or not. (OR)

\section{Individual factors - Perpetrator}

Two main perpetrator characteristics or beliefs were perceived as being relevant to their use of sexual violence in relationships. These were often in addition to other factors that are common to IPV more broadly such as a lack of respect for women or adherence to traditional gender roles:

\section{Entitlement to sex}

Many of the participants described their partner's conviction that he was entitled to sex whenever, and however, he felt like it.

Within my marriage it was - there was definitely this sense of entitlement, and the justification was, 'Well I just wanted to have sex with my wife. And I know it was wrong, and I know it hurt her, but I just wanted to - and I'm really sorry, but I can't promise I won't do it again.' (ML)

So he would just come in, accuse me of doing all sorts of things and he would just force himself pretty much on me. I'd say no but he - he actually said that I was his wife and I was his property and he could do as he wishes (LM)

He had a sex drive that was just ridiculous, and I guess he just thought that he was entitled to have it met. That it was his partner's duty. (MB)

This sense of entitlement extended to the perpetrator penetrating a woman vaginally or anally while she was asleep, even when she had previously expressed her wishes not to engage in sexual activity: 
I woke up, I don't know what time of the morning, or night, that it was. My husband had his fingers in my vagina, so it was sexual penetration and I had to actually push him off and he tried to sort of just go, 'There, there, it's okay, it's fine'. I really fought him off and just said, 'If you want that kind of thing you ask for it, you don't just take it whenever you like!' (KK)

There was a few times there where I'd just sort of kick, like physically I'd kick out at him and kick him away and yell at him and say, 'I've told you, don't you ever, ever do that again!' Then he'd just sort of - he'd always back off, so he'd roll over and just grumble and turn away and go to sleep, or he'd leave the room and go and sleep on the couch. But we didn't speak about it during the day, so the next day it was just unspoken. There was one time I even said to him - I didn't believe it at the time - but yeah, I woke up and he was putting himself into my bum which just - like I absolutely hated. (LW)

\section{Compensation for fragile masculinity}

Additionally, several women stated that they felt that the perpetrator was compensating for some form of internalised sense of sexual inadequacy. Often, this was perceived as insecurity around their heterosexuality and masculinity.

The weird thing is that I don't think he actually really liked sex... I don't think he did in any way, certainly not with females anyway. (BB)

I think he was physically incapable that weekend of having sex himself, but he was going to make sure that I knew that he was still the boss, is how I viewed that after it had happened. (UC)

He was completely obsessed with the belief that I was in love with Italians - not just one but all of them - and that I liked bigger men and all this sort of stuff... He used to just badger me about how much bigger was it [previous partner's penis] and how much wider was it than his and - you know? (LM)

I think they [perpetrators] are scared of other males. (TT)

\section{Relationship factors}

When speaking about their relationships, women repeatedly described the unequal power dynamics that were present. This was related to two main factors:

\section{Large age gap in the relationship}

As previously identified, many of the women were quite young when they entered into the relationship; the perpetrator was often considerably older than them and more experienced. 
He was older than me. He was probably 10 to 12 years older than me, I think. No, maybe even more. Maybe 15 years older than me. (DA)

He was 25 years older than me, so I was 17 , just before I was 18 , and he was 42 . So there was obviously a massive power imbalance there, that I thought was fine [laughs]. I thought that I was in control and that was all fine, and I was an adult in that situation, which clearly in retrospect, I was not an adult in that situation. (LB)

\section{Controlling behaviour and psychological abuse}

Many women described a pattern of controlling behaviour and psychological abuse within the relationship in addition to the sexual violence.

I was never allowed to go to bed after him. I always had to go to bed when he did. (GP)

I wasn't in contact with any of my friends because he didn't want me to be. He would monitor my social media and my text messaging, so my phone basically, at any time. Especially when I was sleeping, he would go through my phone, delete contacts who were male, on Facebook who were male. (NG)

I had to put certain dresses. I had to wear high heels. I was not allowed to really go for longer than 10 minutes to the supermarket. He'd ring me if I'd stay away for too long...I couldn't walk the dog on the beach. If I did it was 20 minutes and I would get a call because he wanted a blow job. (KW)

I'd moved in to the back room and he would pace outside my room in the middle of the night. I would hear him at 12, one o'clock in the morning, just outside the room, walking backwards and forwards. I was getting to the stage where I was putting furniture up against the door. (SD)

\section{Community factors}

Beyond the relationship itself, other factors within the woman's broader community also may have contributed to an environment where IPSV went unrecognised and unaddressed.

\section{Trapped and isolated}

Most of the women lacked a support network of friends and family, either because they were physically isolated from them, or because of conflict or dysfunction. This meant that they were dependent on the perpetrator financially or emotionally. This vulnerability was exploited by the perpetrator as a way of forcing the woman to have sex. For other women, having children with the perpetrator made them feel trapped and unable to leave the abusive relationship. 
I didn't feel I could go back to my mother because she would - I never - I felt I needed to stay in that marriage. I felt insecure. There was no sense of me leaving it because I didn't know where I could go and I had two children at this stage. (AD)

He'd want to do stuff that I wasn't comfortable with. Yeah, you felt you had to because I had nothing. I had no money of my own. I had no transport of my own. (EK)

The majority of women will stay in an abusive relationship because of financial reasons. Yeah, and so even if you're having unwanted sex with someone you're staying with them for longer. For me I didn't have a safe place in my family or community or anywhere that I could go. (DL)

I come from a pretty conservative family, and I was pretty depressed and unhappy, and I didn't really feel like I was getting much support at home, or that I was very good at making friends. I was feeling pretty isolated. (TC)

\section{Talking about your sex life is taboo}

Even when women did have friends or family to support them, they did not feel able to speak openly about their sexual relationships.

I think that women's sexuality in general is still not a topic that is socially acceptable to talk about very much. So that makes it hard. (IJ)

Yeah, I think that there's definitely more shame for people to speak out about it [IPSV], and more fear to speak out about it. (DL)

I never really talked about that [IPSV] because I was embarrassed and I didn't want to do it, so I wouldn't have even said it to my best friend. (LW)

I was so ashamed of it...It wasn't something that I brought up at all. I was making sure that everything was fantastic, but it wasn't. It's such a grey area. Where do you start? What do you say? (SC)

\section{Services address physical and emotional but not sexual}

When women did eventually seek help or leave the perpetrator, they often encountered barriers to addressing the sexual violence in particular. Police were often unable or unwilling to do anything about the IPSV due to the difficulty in proving that an assault had taken place. Specialist services for IPV often only asked about physical or emotional abuse without enquiring about sexual. 
I just feel like you don't really know that it's not normal because it's not talked about... Noone talks about that sexual element. It's all focused on physical and emotional, financial, all that stuff. (FR)

When people talk about physical assaults and financial and emotional, that's fine. Legitimately I'm a victim in all of those things. When you start talking about sexual things everybody is very, very uncomfortable. (OL)

\section{Societal factors}

Lastly, at the societal level, a number of IPSV-supportive attitudes were identified by the participants.

\section{Duty to give men sex}

Pressure to be sexually available came not only from the women's partners, but also from society. Women identified an internalised sense of duty to engage in sex regularly, even when they did not want to.

I'd always thought I was sort of obliged to at least give a blow job if I didn't actually have sex. That was probably something my first boyfriend put on me as well, not to mention society. It's - the grooming probably comes from everywhere. (OR)

I worked really hard to try to be more sexually available and to want to be interested in sex, because I felt like that's what I should be doing. (TV)

She said you get to the point where you just have to prostitute yourself sometimes in order to keep your husband happy. (KK)

Participants identified pornography as playing a part to some extent in shaping this view of women as sexually available and willing to acquiesce to their partner's demands.

I feel it's so pervasive, there's such a high pressure on us from men to experiment and do whatever, like it's such a battle. (OV)

Men completely feel entitled. I think porn is a massive issue, something that I thought was cool when we were together, I was like, yeah, I like porn. Everyone likes porn, that's great. But I really do feel like that massively impacts the way that women are treated (LB)

Similarly, the idea that men need sex biologically was raised as a justification for why women should engage in unwanted sex.

He'd always talked about how he was very sexual and how he was - it's just normal for men to be very, very, very sexual and how there's nothing he can do about it kind of thing. (BP) 
I suppose as much as I attribute it to him specifically the pressure from me I feel coming from the whole of society, this idea that men need a certain amount of sex, that if a man gets turned on and then you deny him it somehow hurts him. (OR)

Everyone has an idea of what "real rape" is

Women felt that IPSV was poorly understood within wider society compared with sexual assault perpetrated by a stranger. They believed that most people's idea of "real rape" is a physically violent assault that happens in a dark alleyway rather than something that happens at home. Furthermore, they felt that education and information about sexual relationships did not cover "grey areas" where consent was more ambiguous.

He [perpetrator] doesn't look like what people think a rapist looks like. I mean people will see him and think, well he can easily get women. So people don't see it as what it is. Maybe it's partly an education of the general population that somebody doesn't look like this crazy sort of dude in vagrant clothing to be a rapist. (BS)

...Because it's a really grey area... you know, sexual abuse. Especially if you're actually in a partnership. Because you don't know what is actually - sometimes - nobody really defines, you know, what is okay and what's not okay in terms of sex in a partnership. (SC)

I think that stranger assault - sexual assault - sexual assault by a stranger - I think I personally would prefer that over what I experienced. Because - I don't know - people seem to 'get' that and why it's wrong and why it's such a violation and how it would make someone feel. (MO)

\section{Discussion}

This study is the first to take an ecological view of IPSV, examining the individual, relationship, community and societal factors that are unique to this hidden form of violence against women. Viewed together, it is clear how factors across all levels interact to create a "perfect storm" where IPSV is allowed to go unrecognised and underreported (see Figure 2). 
Figure 2. Ecological model of IPSV

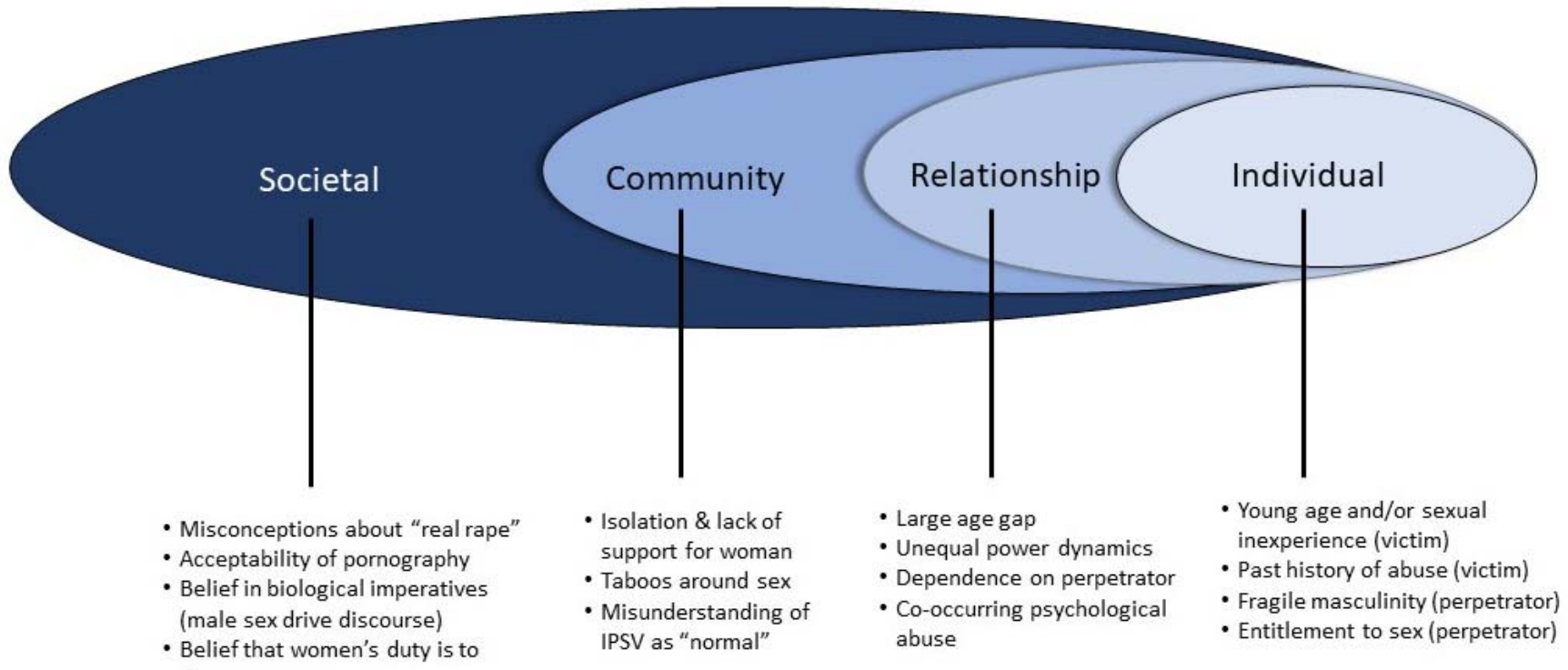

Consistent with existing literature on sexual assault revictimization (Classen, Palesh, \& Aggarwal, 2005; Grauerholz, 2000), the women in this study identified past sexual abuse, IPV and trauma as factors that may have contributed towards their vulnerability to IPSV. The reasons why these experiences are risk factors for sexual violence are not clear, although hypotheses include that the resulting mental health issues make one more susceptible to revictimization (Grauerholz, 2000). The findings of this study were certainly consistent with this theory, however, what is novel is that they highlight how women's past sexual or emotional trauma (whether experienced as a child or as an adult) was explicitly used by perpetrators as a way of gaslighting them into believing their dislike of the sexual acts they were being forced to perform was abnormal. Similarly, for many of the women, their young age and sexual inexperience was used against them by the perpetrator, taking advantage of their poor knowledge of healthy relationships to normalise the violence. This was compounded in relationships where there was a large age gap and co-occurring psychological abuse. These findings expand upon existing knowledge around IPV risk factors. Younger women are already known to be a high-risk group for IPV (Australian Bureau of Statistics, 2017; World Health Organization, 2013), yet in the case of IPSV it was a combination of young age, sexual inexperience, and an older partner that was identified as being relevant. This differs from the SV literature which suggests that it is multiple sexual partners, rather than inexperience, that increases women's level of risk (World Health Organization, 2010).

There is a paucity of literature on the individual characteristics of perpetrators of IPSV, although some research has examined traits associated with perpetration of sexual assault (Loh, Gidycz, Lobo, \& Luthra, 2005; Tharp et al., 2013) and IPV (Love, Spencer, May, Mendez, \& Stith, 2018) 
more broadly (World Health Organization, 2010). In the IPV context, the role of "hegemonic masculinity" (Connell, 1987) (often referred to as "support for traditional gender roles" or "hyper masculinity”) has been acknowledged as being central (Forsdike, Tarzia, Flood, Vlais, \& Hegarty, 2018; Peralta \& Tuttle, 2013), both as a force that shapes violence-supportive attitudes, and as a trigger for violent acts when it is threatened (Anderson \& Umberson, 2001; Gallagher \& Parrott, 2011). Peralta and Tuttle (Peralta \& Tuttle, 2013), for instance, have highlighted the relationship between IPV perpetration and threats to masculinity in the context of financial insecurity. In the sexual violence context, the role of hegemonic masculinity has received less attention (Messerschmidt, 2000), although the literature suggests a similar relationship (Flood, 2007; Gallagher \& Parrott, 2011). In the present study, women perceived that their partners felt entitled to sex and - if they did not acquiesce - would use threats or violence to obtain it. Masculinity, then, in the IPSV context, can be understood as the aggressive sexual conquest of women, who then become sexual "property"(Easteal \& McOrmond-Plummer, 2006) to whom a man is entitled unlimited access. Where the perpetrator's sense of his own masculinity was fragile, the violence was used as a way to confirm and reinforce the perpetrator's masculinity and heterosexuality. Messerschmidt (Messerschmidt, 2000) outlines a similar finding in his life history study of adolescent male perpetrators of sexual violence. Quantitative studies also suggest associations between "gender role stress" and sexual violence (Gallagher \& Parrott, 2011), although the nuances of this relationship are unclear. Syntheses of the extant literature on both IPV and sexual assault perpetration also acknowledge the role of childhood maltreatment, family dysfunction, antisocial personality, alcohol or substance misuse, gang membership, previous sexual violence perpetration and peer group influence in men's use of violence (Tharp et al., 2013; World Health Organization, 2010), however, these factors were not identified by the women in this study. More research is needed into the specific characteristics of IPSV perpetrators in order to understand how their motivations might differ from the broader contexts of IPV and sexual assault of strangers.

At the community level, women's isolation from friends and family and/or lack of support networks were identified as contributors. Participants felt trapped and unable to leave the perpetrator, especially when there were children in the relationship. Although isolation tactics also occur in other types of IPV, it was particularly challenging for these women given that their vulnerability was often exploited by the perpetrator as a way of blackmailing them into sex. Even when they did have support from friends and family, women still did not feel able to discuss the sexual abuse that was happening in their relationships. There was a sense that sex was a private matter that women were embarrassed or ashamed to discuss. Other studies on IPSV also highlight this issue (Easteal \& McOrmond-Plummer, 2006; Logan \& Cole, 2011; Logan, Cole, \& Shannon, 2007; Logan et al., 2015). This discomfort with the topic of sex extended to service providers, who enquired about physical or psychological abuse without addressing the sexual violence. Parkinson, in her study of rural women's experiences of IPSV, described a similar problem with help-seeking (Parkinson, 2008; Parkinson \& Reid, 2014). Although sexual assault services are more equipped to discuss the issue, most women in this study did not identify their experiences as "rape" or "sexual violence" (Bergen, 1995) and thus did not access these. Researchers have warned that this invisibility of IPSV within the justice system and the specialist women's sector can lead to 
"secondary wounding" (McOrmond-Plummer, Easteal, \& Levy-Peck, 2014), increasing the toll on women's health and wellbeing. It is critical that taboos around sex not get in the way of effective responses to IPSV.

At the societal level, many women described the sense of duty they felt to have sex with their male partners, or to try and enjoy the often painful and degrading acts they were forced to perform. Although other studies have described the perpetrator telling women that sex was her "wifely duty" (Logan et al., 2007), women in this study spoke of a more internalised sense of duty that came from wider society. Having, and enjoying sex with one's partner was what they felt they were "supposed" to do in order to maintain a happy relationship. Pornography was identified as one source of this social pressure, responsible for mainstreaming the idea that women are endlessly available and willing to have sex (Dines, 2011). The participants also raised the popular (yet inaccurate) theory that men need sex biologically as a factor that contributed towards their sense of obligation and helped justify the perpetrator's behaviour. National community surveys in Australia similarly demonstrate support for these myths (Webster et al., 2018). Elsewhere, it has been argued that the popularisation of these myths about the male sex drive are harmful (Tarzia, 2015), and "scaffold" sexual violence (Gavey, 2005), yet this issue has not been previously addressed in the context of IPSV.

The final societal-level factor identified in the data was the idea that "real rapes" are perpetrated by strangers; what happens in the privacy of one's bedroom is more likely to be misconstrued, as one participant put it "as a sex game gone wrong". IPSV researchers have long flagged this issue as a barrier to disclosure for women, and to early engagement and response by services (Bergen, 1996; Easteal \& McOrmond-Plummer, 2006; Finkelhor \& Yllo, 1985; McOrmond-Plummer et al., 2014; Parkinson \& Reid, 2014), yet it appears that little has been done to shift this cultural paradigm (Webster et al., 2018). Furthermore, the complex dynamics of consent within an intimate relationship are also poorly understood. There is a lack of knowledge around how coercive tactics, blackmail, and implicit threats can be used as strategies to force women into having sex without the perpetrator having to utilise physical force. Instead, social discourse and sex education tends to focus on simplistic "No means no" messaging. Consequently, women are left wondering whether what they have experienced is a form of violence, or simply normal relationship behaviour, particularly when they have no frame of reference with which to compare it.

As the findings of this study show, IPSV is a complex phenomenon that has many overlaps with both IPV and sexual violence across various levels of the ecological model (see Table 2). Yet, it seems that there are also a range of differences - some subtle and some more obvious - that set it apart. A global research synthesis by the World Health Organization (2010), for instance, identified risk factors such as poverty, poor education, and unemployment for both perpetration and victimisation of IPV and sexual violence. Yet, none of these factors were mentioned by the participants and overall the sample in this study was predominantly well-educated and employed. Similarly, as mentioned above, having multiple partners or infidelity in relationships was associated with both IPV and sexual violence perpetration and victimisation (Tharp et al., 2013; 
World Health Organization, 2010), yet again, this was not a common theme amongst the participants in this study. Consequently, I suggest that factors relating to IPSV in particular ought to be investigated further and incorporated into prevention frameworks going forward.

\begin{tabular}{|l|l|}
\hline IPSV risk factors & Also present in... \\
\hline Young age (victim) & IPV \\
\hline Sexual inexperience (victim) & - \\
\hline Past history of abuse (victim) & IPV \& SV \\
\hline Entitlement (perpetrator) & IPV \& SV \\
\hline Fragile masculinity (perpetrator) & IPV \& SV \\
\hline Large age gap in relationship & - \\
\hline Co-occurring psychological abuse & - \\
\hline Isolation / lack of support & IPV \\
\hline Taboos around sex & SV \\
\hline Sex as a private matter & - \\
\hline Services not equipped to respond & - \\
\hline Duty to provide sex & - \\
\hline Pornography & SV \\
\hline Male sex drive discourse & SV \\
\hline Misconceptions about 'real rape' & - \\
\hline
\end{tabular}

Table 2. Ecological risk factors and overlaps with IPV and SV

\section{Limitations}

Although study recruitment materials aimed to be inclusive of diverse participants, the sample were predominantly born in Australia, educated, and did not identify as Aboriginal or Torres Strait Islander. As there are likely to be high rates of IPSV in both Aboriginal and Torres Strait Islander and culturally and linguistically diverse communities, it is vital that the experiences of these women are incorporated into future refinements of the suggested ecological model. Similarly, while not all the women currently identified as heterosexual, all the experiences of IPSV were perpetrated by a male partner. It is important to capture the experience of IPSV in women's samesex relationships to explore the differences and similarities.

\section{Conclusion}

IPSV shares characteristics with both IPV and sexual violence but is more complex than simply combining these two prevention and response frameworks into one. In this paper I have explored individual, relationship, community and societal factors that, from the perspective of women victim/survivors, may be relevant to IPSV, and developed an integrated ecological model that is unique to IPSV. Given that the data drawn upon is qualitative and represents only the perceptions of the participants in this study, the suggested ecological model is only preliminary. It highlights further areas for exploration with large-scale quantitative studies that would provide data confirming associations between individual, relationship, community and societal factors and IPSV. 


\section{References}

Anderson, K., \& Umberson, D. (2001). Gendering Violence: Masculinity and Power in Men's Accounts of Domestic Violence. Gender \& Society, 15(3), 358-380.

Australian Bureau of Statistics. (2017). Personal Safety Survey. Retrieved from Canberra, Australia: http://www.abs.gov.au/ausstats/abs@.nsf/mf/4906.0

Bagwell-Gray, M. E., Messing, J. T., \& Baldwin-White, A. (2015). Intimate Partner Sexual Violence: A Review of Terms, Definitions, and Prevalence. Trauma, Violence and Abuse, 16(3), 316-335.

Basile, K. C., Smith, S., Liu, Y., Kresnow, M., Fasula, A., Gilbert, L., \& Chen, J. (2018). RapeRelated Pregnancy and Association With Reproductive Coercion in the U.S. American Journal of Preventive Medicine, 55(6), 770-776.

Bergen, R. K. (1995). Surviving Wife Rape: How Women Define and Cope With the Violence. Violence Against Women, 1(2), 117-138.

Bergen, R. K. (1996). Wife Rape: Understanding the Response of Survivors and Service Providers. Thousand Oaks, USA: Sage Publications.

Black, M. C., Basile, K. C., Breiding, M. J., Smith, S., Walters, M. L., Merrick, M. T., . . Stevens, M. (2010). The National Intimate Partner and Sexual Violence Survey: 2010 Summary Report. Retrieved from Atlanta USA:

Braun, V., \& Clarke, V. (2019). Reflecting on reflexive thematic analysis. Qualitative Research in Sport, Exercise and Health, 11(4), 589-597.

Campbell, J., \& Soeken, K. (1999). Forced Sex and Intimate Partner Violence: Effects on Women's Risk and Women's Health. Violence Against Women, 5(9), 1017-1035.

Classen, C., Palesh, O., \& Aggarwal, R. (2005). Sexual Revictimization: A Review of the Empirical Literature. Trauma, Violence and Abuse, 6(2), 103-129.

Connell, R. (1987). Gender and Power: Society, the Person and Sexual Politics. Palo Alta, California: University of California Press.

Cox, P. (2015). Violence against women in Australia: Additional analysis of the Australian Bureau of Statistics' Personal Safety Survey 2012. ANROWS Horizons: 01/2015. Retrieved from Sydney, Australia: http://media.aomx.com/anrows.org.au/s3fspublic/151022\%20Horizons \%201.1\%20PSS.pdf

Cramer, E., McFarlane, J., Parker, B., Soeken, K., Silva, C., \& Ree, S. C. (1998). Violent pornography and abuse of women: Theory to practice. Violence \& Victims, 13, 319-332.

Dines, G. (2011). Pornland: How Porn Has Hijacked Our Sexuality. Melbourne, Australia: Spinifex Press.

Easteal, P., \& McOrmond-Plummer, L. (2006). Real Rape, Real Pain: Help for women sexually assaulted by male partners. Melbourne: Hybrid Publishers.

Finkelhor, D., \& Y1lo, K. (1985). License to Rape: Sexual Abuse of Wives. New York: Free Press.

Flood, M. (2007). Men, Sex, and Homosociality: How Bonds between Men Shape Their Sexual Relations with Women. Men \& Masculinities, 10(3), 339-359.

Forsdike, K., Tarzia, L., Flood, M., Vlais, R., \& Hegarty, K. (2018). “A Lightbulb Moment”: Using the Theory of Planned Behavior to Explore the Challenges and Opportunities for Early Engagement of Australian Men Who Use Violence in Their Relationships. Journal of Interpersonal Violence, Online first, 1-25. doi:org/10.1177/0886260518780778 
Fulu, E., \& Miedema, S. (2015). Violence Against Women: Globalizing the Integrated Ecological Model. Violence Against Women, 21(12), 1431-1455.

Gallagher, K., \& Parrott, D. (2011). What accounts for men's hostile attitudes toward women? The influence of hegemonic male role norms and masculine gender role stress. Violence Against Women, 17(5), 568-583.

Gavey, N. (2005). Just Sex?: The Cultural Scaffolding of Rape. Sussex UK: Routledge.

Grauerholz, L. (2000). An Ecological Approach to Understanding Sexual Revictimization: Linking Personal, Interpersonal, and Sociocultural Factors and Processes. Child Maltreatment, 5(1), 5-17.

Heise, L. (1998). Violence against women: an integrated, ecological framework. Violence Against Women, 4(3), 262-290.

Katz, J., Moore, J., \& May, P. (2008). Physical and Sexual Covicimization From Dating Partners: A Distinct Type of Intimate Abuse? Violence Against Women, 14(3), 961-980.

Logan, T. K., \& Cole, J. (2011). Exploring the intersections of partner stalking and sexual abuse. Violence Against Women, 17, 904-924.

Logan, T. K., Cole, J., \& Shannon, L. (2007). A mixed-methods examination of sexual coercion and degradation among women in violence relationships who do and do not report forced sex. Violence and Victims, 22, 71-94.

Logan, T. K., Walker, R., \& Cole, J. (2015). Silenced Suffering: The Need for a Better Understanding of Partner Sexual Violence. Trauma Violence \& Abuse, 16(2), 111-135.

Loh, C., Gidycz, C. A., Lobo, T., \& Luthra, R. (2005). A Prospective Analysis of Sexual Assault Perpetration: Risk Factors Related to Perpetrator Characteristics. Journal of Interpersonal Violence, 20(10), 1325-1348.

Love, H., Spencer, C., May, S., Mendez, M., \& Stith, S. (2018). Perpetrator Risk Markers for Intimate Terrorism and Situational Couple Violence: A Meta-Analysis. Trauma, Violence and Abuse, Online first.

Malamuth, N., Sockloskie, R., Koss, M., \& Tanaka, J. (1991). Characteristics of Aggressors Against Women: Testing a Model Using a National Sample of College Students. Journal of Consulting and Clinical Psychology, 59(5), 670-681.

McOrmond-Plummer, L. (2014). Considering the Differences: Intimate partner sexual violence in sexual assault and domestic violence discourse. In L. McOrmond-Plummer, P. Easteal, \& J. Levy-Peck (Eds.), Intimate Partner Sexual Violence: A Multidisciplinary Guide to Improving Services and Support for Survivors of Rape and Abuse. London: Jessica Kingsley Publishers.

McOrmond-Plummer, L., Easteal, P., \& Levy-Peck, J. (Eds.). (2014). Intimate Partner Sexual Violence: A multidisciplinary guide to improving services and support for survivors of rape and abuse. London: Jessica Kingsley Publishers.

Mealer, M. (2013). Methodological and ethical issues related to qualitative telephone interviews on sensitive topics. Nurse Researcher, 21(4), 32-37.

Messerschmidt, J. (2000). Becoming 'Real Men': Adolescent Masculinity Challenges and Sexual Violence. Men \& Masculinities, 2(3), 286-307.

Our Watch, Australia's National Research Organisation for Women's Safety (ANROWS), \& VicHealth. (2015). Change the story: A shared framework for the primary prevention of violence against women and their children in Australia. Retrieved from Melbourne: 
Parkinson, D. (2008). Raped by a partner: Nowhere to go, no-one to tell. Retrieved from Wangaratta VIC:

Parkinson, D., \& Reid, S. (2014). 'Invisible' Intimate Partner Violence: Prevention and Intervention Challenges. In L. McOrmond-Plummer, P. Easteal, \& J. Levy-Peck (Eds.), Intimate Partner Sexual Violence: A Multidisciplinary Guide to Improving Services and Support for Survivors of Rape and Abuse (pp. 136-146). London: Jessica Kingsley Publishers.

Peralta, R., \& Tuttle, L. (2013). Male Perpetrators of Heterosexual-Partner-Violence: The Role of Threats to Masculinity. Journal of Men's Studies, 21(3), 255-276.

Reilly, J. M., \& Gravdal, J. A. (2012). An Ecological Model for Family Violence Prevention Across the Life Cycle. FAMILY MEDICINE, 44(5), 332-335.

Simmons, C., Lehman, P., \& Collier-Tenison, S. (2008). Linking Male Use of the Sex Industry to Controlling Behaviors in Violent Relationships: An Exploratory Analysis. Violence Against Women, 14(4), 406-417.

Tarzia, L. (2015). From Marriage Manuals to Mars and Venus: Darwin, Sex Advice and the Promotion of Inequality. Women's Studies, 44, 368-391.

Tarzia, L., Humphreys, C., \& Hegarty, K. (2017). Translating research about domestic and family violence into practice in Australia: possibilities and prospects. Evidence \& Policy, 13(4), 709-722.

Tarzia, L., Thuraisingam, S., Novy, K., Valpied, J., Quake, R., \& Hegarty, K. (2018). Exploring the relationships between sexual violence, mental health and perpetrator identity: A crosssectional Australian primary care study. BMC Public Health, 18(1410).

Tarzia, L., Valpied, J., Koziol-McLain, J., Glass, N., \& Hegarty, K. (2017). Methodological and ethical challenges in a web-based randomized controlled trial of a domestic violence intervention. Journal of Medical Internet Research, In Press.

Tarzia, L., Wellington, M., Marino, J., \& Hegarty, K. (2018). 'A huge, hidden problem': Australian health practitioners' views and understandings of reproductive coercion. Qualitative Health Research, Online first.

Tharp, A. T., DeGue, S., Valle, L., Brookmeyer, K., Massetti, G., \& Matjasko, J. (2013). A Systematic Qualitative Review of Risk and Protective Factors for Sexual Violence Perpetration. Trauma, Violence and Abuse, 14(2), 133-167.

Wall, L. (2012). Research Report: The many facets of shame in intimate partner sexual violence. Retrieved from Melbourne:

Webster, K., Diemer, K., Honey, N., Mannix, S., Mickle, J., Morgan, J., . . . Ward, A. (2018). Australians' attitudes to violence against women and gender equality. Findings from the 2017 National Community Attitudes Survey (NCAS). Retrieved from Sydney NSW:

World Health Organisation (WHO), \& London School of Hygiene and Tropical Medicine. (2010). Preventing intimate partner and sexual violence against women: taking action and generating evidence. Retrieved from Geneva, Switzerland:

World Health Organization. (2010). Preventing intimate partner and sexual violence against women: taking action and generating evidence. Retrieved from Geneva:

World Health Organization. (2013). Global and regional estimates of violence against women: prevalence and health effects of intimate partner violence and non-partner sexual violence. In. Geneva, Switzerland: WHO. 